\title{
Effects of toe and ankle training in older people: a cross-over study.
}

AUTHOR(S):

Nagai, Koutatsu; Inoue, Takuya; Yamada, Yosuke; Tateuchi, Hiroshige; Ikezoe, Tome; Ichihashi, Noriaki; Tsuboyama, Tadao

\section{CITATION:}

Nagai, Koutatsu ... [et al]. Effects of toe and ankle training in older people: a cross-over study.. Geriatrics \& gerontology international 2011, 11(3): 246-255

\section{ISSUE DATE:}

2011-01-04

URL:

http://hdl.handle.net/2433/196638

\section{RIGHT:}

(c) 2011 Japan Geriatrics Society; This is the peer reviewed version of the following article: Nagai, K., Inoue, T., Yamada, Y., Tateuchi, H., Ikezoe, T., Ichihashi, N. and Tsuboyama, T. (2011), Effects of toe and ankle training in older people: A cross-over study. Geriatrics \& Gerontology International, 11: 246-255., which has been published in final form at http://dx.doi.org/10.1111/j.1447-0594.2010.00673.x; This is not the published version. Please cite only the published version.; この論文は出版社版でありません。引用の際には出版社版をご確認ご利用ください。 


\section{Effects of Toe and Ankle Training in Older People:}

\section{A Cross-Over Study}

Koutatsu Nagai, RPT, MS ${ }^{1}, \quad$ Takuya Inoue, RPT, $\mathrm{MS}^{2}, \quad$ Yosuke Yamada, $\mathrm{PhD}^{3}$, Hirosige Tateuchi, RPT, MS ${ }^{1}$, Tome Ikezoe, RPT, $\mathrm{PhD}^{1}$, Noriaki Ichihashi, RPT, $\mathrm{PhD}^{1}$, Tadao Tsuboyama, $\mathrm{MD}, \mathrm{PhD}^{1}$

${ }^{1}$ Human Health Sciences, Graduate School of Medicine Kyoto University

${ }^{2}$ Rihabirinokaze home-visit nursing care station Co. Ltd

${ }^{3}$ The Fukuoka University Institute for Physical Activity

E-mail: k.nagai@ky2.ecs.kyoto-u.ac.jp

Department of Physical Therapy, Kyoto University, Kyoto, Japan 53, Kawahara-cho, Shogoin, Sakyo-ku, Kyoto, 606-8507, Japan

Phone: +81-75-751-3948

Fax: +81-75-751-3948

\section{Address:}

${ }^{2}$ Rihabirinokaze home-visit nursing care station Co. Ltd, Tokyo, Japan 13-1-2, Takawa taunhausu 209, takawa, minato-ku, Tokyo, 108-0074, Japan

${ }^{3}$ The Fukuoka University Institute for Physical Activity, Fukuoka, Japan 8-19-1

Nanakuma, Jonan-ku, Fukuoka 814-0180, Japan

Running head: Effects of Toe and Ankle Training in Older People 


\begin{abstract}
Aim: Maintenance of physical function in the elderly is important. Previous studies have focused mainly on training-center-based interventions, accompanied by training staff or equipped with training machinery. The purpose of this study was to investigate the effects of toe and ankle training for the elderly.

Methods: The four facilities were divided into two groups that received the intervention in 8-week shifts. An exercise program, focused mainly on ankle, foot and toe function, was conducted with the subject in a sitting position. Muscle strength, physical function, fear of falling and health-related quality of life were assessed at the beginning of the study and at the end of each 8-week phase. Because subjects were not randomized, significant inter-group differences were present in some baseline measurements. Therefore, the study was conducted with a cross-over design, and an analysis of covariance was included with the baseline value as an independent covariate.

Results: A significant improvement was found in quadriceps strength, functional reach, stepping in sitting and Euro Qol, together with a possible improvement in toe flexor force.

Conclusion: These results suggest that a training program carried out with the subject in a sitting position and focused mainly on ankle, foot and toe functions is effective in improving some aspects of motor function in the elderly. This approach may help elderly individuals maintain their activity level without increasing risks.
\end{abstract}

Key wards: toe training, older people, sitting position, ankle training, cross-over design 


\section{Introduction}

Declines in muscle strength and physical function in older people induce infirmity and necessitate nursing care. The maintenance of muscle strength and physical function in the elderly is especially important, not only for avoiding nursing needs and reducing medical bills, but also for improving quality of life (QOL). Numerous studies have shown improvements in muscle strength and physical function with training, even into advanced age. Resistance training is the most common method of intervention for the improvement of muscle strength in the elderly, as it is effective in promoting muscle strength ${ }^{1-2}$. In a systematic review, improvement in mobility was also reported with resistance training ${ }^{3}$. Some studies have shown the effectiveness of multiple forms of training, including gait exercise, balance exercise, aerobic exercise, and educational programs ${ }^{4-7}$.

Most studies have focused on training-center-based interventions, accompanied by training staff and training equipment ${ }^{1-2,4-9}$. However, not all elderly individuals can benefit from these training-center based interventions. Some lack adequate access to the training-center, and some are too frail to perform resistance training. Home-based, multiple-format training programs that include resistance training and balance exercise have also resulted in muscle strength and physical function improvements in older people ${ }^{10-11}$, but unaccompanied training that involves standing carries a risk of falls for frail people.

Ideally, the welfare system could send expert staff frequently to all elderly individuals in the community. In practice, a safe and effective method of self-training would be highly beneficial for functionally impaired elderly individuals who can barely stand and walk.

Some reports have shown that toe function affects dynamic balance and mobility. Toes play an important role during the propulsion phase of gait ${ }^{12}$. Toes also serve to maintain posture in unstable conditions, such as a single-leg stance or standing on a soft surface, such as a mat ${ }^{13-14}$. Ihara and colleagues reported that toe/sole training improved 
muscle strength and physical functions, such as toe flexor strength, ankle strength, center of gravity sway, and repetitive side steps, and these effects were maintained after two months ${ }^{15}$. Toe training can be performed safely, even by elderly individuals who are at risk of falls, with the individual in a sitting position. However, little has been reported on the effect of toe and ankle training on older people. A physical function such as balance ability might be improved according to improvement of toe and ankle function in older people. The improvement of physical function such as balance ability reduces the risk of falling in older adults ${ }^{16}$. In this study, an exercise program focused mainly on toe and ankle function was developed as a low-intensity training method that could be carried out without supervision. The objective of this study was to investigate the effects of the toe and ankle training on elderly people.

\section{Methods}

\section{Study Design}

The trial was a cross-over study conducted in four participating nursing homes. All facilities were located in the suburbs without major inter-home differences in the environment and services provided. The study was comprised of the following steps: ( I ) subject screening and enrollment, ( II ) baseline assessments, ( III ) an immediate-intervention phase, in which subjects in two of the facilities received the intervention (immediate-intervention group: Group 1) for 8 weeks, while subjects in the other two nursing homes served as controls (delayed-intervention group: Group 2), and (IV) a delayed-intervention phase, during which subjects in Group 2 received the intervention for 8 weeks. Outcome measures were assessed at the beginning of the study and at the end of each phase.

\section{Subjects}


The study subjects were sampled from four nursing homes in Kyoto, Japan. A document describing the aim and content of the study was given to the four facilities, and each agreed to cooperate. Oral and written explanations of the study were offered to all residents. Subjects were excluded if they had neurological impairment (acute stroke, Parkinson's disease, paresis of the lower limbs), severe cardiovascular disease (acute myocardial infarction, congestive heart failure, uncontrolled hypertension), unstable chronic or terminal illness (uncontrolled diabetes mellitus, malignancies), major depression, severe cognitive impairment (inability to follow training instructions, confirmed either by the clinical diagnosis of dementia or by the direct verbal exchange for the explanation of the study procedure), or severe musculoskeletal impairment (inability to participate in the training regimen). One-hundred-eighteen subjects resided in four facilities. Sixty individuals refused to participate in the study, and 4 did not meet the inclusion criteria. Fifty-four individuals of mean (standard deviation [SD]) age 83.0 (6.8) years agreed to participate in the study and provided written consent. The four facilities were divided into two groups (the immediate-intervention group: Group 1 and the delayed-intervention group: Group 2), each consisting of 2 facilities, so as to keep the numbers of subjects in the 2 groups as similar as possible. Groups 1 and 2 contained 23 elderly people (21 women, 2 men) of mean (SD) age 81.2 (7.7) years and 31 elderly people (26 women, 5 men) of mean (SD) age 84.0 (5.7) years, respectively. The written consent was obtained from all participants and patient anonymity was preserved in this study. This research was approved by the Ethical Review Board of Kyoto University Graduate School of Medicine, Kyoto, Japan.

\section{Measurements}

Quadriceps muscle strength, toe flexor strength, balance, agility, and mobility were assessed in all subjects at the beginning of the study and at the end of each phase. 
Research staff members who performed the assessments were blinded to the group allocation of the participants. The psychometric properties, fear of falling and health-related quality of life (HRQOL), were also assessed before and after intervention. All staff members were trained to each test protocol sufficiently, and the same tester did the pre and post measurements.

\section{1) Quadriceps strength}

Quadriceps strength was measured with a hand-held dynamometer (HHD: $\mu$ Tas F-1: ANIMA Co.) during isometric contraction of the knee extensor. The test-retest reliability of this method was reported previously ${ }^{17}$. With the subject in a sitting position, the hip and knee were kept at $90^{\circ}$ angles. The maximal isometric strength was measured after adequate pre-measurement trials. The HHD was placed $25 \mathrm{~cm}$ distal to the knee joint. The measurements were performed bilaterally, and the larger value was adopted. Torque was calculated by multiplying strength by the lever arm $(25 \mathrm{~cm})$, and expressed as the percentage of body weight $(\mathrm{N} \mathrm{m} / \mathrm{kg})$.

\section{2) Toe flexor strength}

Toe flexor force was measured with the HHD during isometric contraction of the plantar flexor muscles of the great toe. With the subject in a sitting position, the foot was placed on a $28 \mathrm{~mm}$-high stool, the great toe was extended over the edge of the stool, and the HHD was inserted under the hallux. A research staff member fixed the ankle and the foot in a neutral position, and the subject was instructed to flex the great toe. The maximal isometric strength was measured after adequate pre-measurement trials. The measurements were performed bilaterally, and the larger value was adopted.

\section{3) Balance}


Balance was assessed by the timed one-leg standing test and the functional reach test. In the timed one-leg standing test, subjects were instructed to raise one leg and to keep their posture without hopping, and the amount of time until the raised leg touched the floor was measured. The maximum value was set at 60 seconds. Each subject received instructions from a staff member, who observed the test from beginning to end. After the trial, participants performed the task once on each leg; the best of the two values was adopted. The test was done with the eyes open and with the eyes closed.

The functional reach test measures the distance that subjects are able to reach forward while maintaining a fixed base. Duncan and colleagues reported that it had good predictive validity for recurrent falls and high test-retest and interobserver reliability ${ }^{18-19}$. The position of the fingertip was determined with the shoulder of the subject flexed at $90^{\circ}$ along a wall. Then, the subjects were instructed to reach as far forward as possible without moving their feet, thus moving the center of gravity forward over a fixed base. Functional reach was defined as the difference between the arm's length and the maximal forward reach.

\section{4) Agility}

Agility was assessed with the stepping test with a repetitive side-stepping tester (TKK5301 TAKEI Co). Subjects were instructed to perform alternate stepping with the right and left legs on the board as quickly as possible for five seconds. The number of steps was adopted as the score. The test was done with the subject sitting and standing.

\section{5) Mobility}

Mobility was assessed with the $10 \mathrm{~m}$ walking test and the timed up-and-go test (TUG) 20

The $10 \mathrm{~m}$ walking test was carried out by asking participants to walk a flat path $14 \mathrm{~m}$ in 
length as fast as possible without running. The examiner measured the time and the number of steps for the middle $10 \mathrm{~m}$. The trial was done once after instruction by a staff member. Walking speed $(\mathrm{m} / \mathrm{s})$ and step cadence (step/min) were calculated as variables.

The TUG test ${ }^{21}$ was modified slightly to obtain maximal abilities, as the test with maximum gait speed showed better prediction for falls and reproducibility than that with self-paced gait ${ }^{22}$. Subjects sat on a chair with armrests. A cone was placed $3 \mathrm{~m}$ in front of the chair. Subjects were instructed to stand up from the chair, walk forward, turn around the cone, return to the chair, and sit down as quickly as possible. After a demonstration by a staff member, participants performed the task once. The time needed to carry out the task was recorded as the score.

\section{6) Fear of falling}

The falls efficacy scale (FES) is based on the operational definition of fear as "low perceived self-confidence at avoiding falls during essential, relatively non-hazardous activities." A modified FES version ${ }^{23}$ translated into Japanese was used. Briefly, subjects were asked how concerned they were about the possibility of falling while performing 10 different activities on a four-category scale from 1 to 4 . The total score on the FES can range from 10 to 40, with low scores indicating greater confidence.

\section{7) Health-related Quality of life}

The Euro Qol EQ5D questionnaire ${ }^{24}$ translated into Japanese was used ${ }^{25-26}$. It comprises a 5-dimensional healthcare classification that includes questions on the status of morbidity, self-care, usual activities, pain/discomfort and anxiety/depression. Participants were asked to indicate their current health status by selecting the most appropriate of three statements about each of the five QOL dimensions. Each statement represents an increasing degree of severity. These five dimensions were combined into a 
health state. Utility values were calculated for these health states, using preferences elicited from a general Japanese population ${ }^{27}$.

\section{Intervention}

The training components were selected specifically to focus on ankles, feet, and toes. All of the exercises were done with the subject in a sitting position. After being given adequate instructions and demonstrations by a research staff member on the first day of the intervention, each subject repeated the training every day for 8 weeks.

From the exercise-participation record, which was checked by facility staff members, the participation rate was calculated for each subject, with the number of days of actual training as the numerator and the total number of days as the denominator, thus giving $100 \%$ when a subject participated in training every day during the intervention phase. The exercise program included 1) alternate heel/toe lifting, 2) towel gathering, 3) beanbag transfer, and 4) weight bearing on toes. The subjects in Groups 1 and 2 underwent the intervention during the immediate-intervention phase (the first 8 weeks) and the delayed-intervention phase (the second 8 weeks), respectively. During the control phases, the first 8 weeks for Group 2 and the second 8 weeks for Group 1 , subjects received no particular instructions and carried out their daily activities as usual. Group 1 subjects were not recommended to continue training during the second 8 weeks. To monitor and supervise the actual exercise repetitively, research staff members visited each facility at least once a week.

\section{1) Alternate heel/toe lifting}

In a sitting position, subjects lifted their heels by plantar-flexing their ankle joints while keeping the tips of their toes on the floor, put down their lifted heels, and then lifted their toes by dorsiflexing their ankle joints while keeping their heels on the floor. This 
alternate movement was repeated 20 times.

\section{2) Towel gathering}

A towel $75 \mathrm{~cm}$ in length was spread out on the floor. The initial positioning of the towel was determined by each participant according to individual preference. Subjects gathered the towel completely with their right toes 5 times and repeated the same task with their left toes. Those who could not gather the towel continued the toe movement for 5 minutes.

\section{3) Beanbag transfer}

Ten beanbags (soft bags made of cloth and filled with beans), about $30 \mathrm{~g}$ each in weight and $4 \mathrm{~cm}$ each in diameter, were placed in a basket $12.5 \mathrm{~cm}$ in height on the floor. The initial positioning of the basket was determined by each participant according to individual preference. Subjects grasped one beanbag with their right toes, brought it out of the basket, and put it on the floor. The remaining beanbags were also transferred one by one in the same way. After all of the beanbags were outside the basket, subjects replaced them in the basket in a similar manner. The same task was repeated with the left toes. Those who could not actually transfer the beanbags continued the grasp/lift trials for 5 minutes.

\section{4) Weight bearing on toes}

The toes were kept in a spread position with web pads. Subjects poised themselves on the anterior part of a chair, bent their trunk forward, and put their weight partially on their toes for approximately 2 seconds. This action was repeated 20 times and after a short break, another 20 times. 


\section{Statistical analysis}

Data collected at each session were entered into SPSS (SPSS ver.12.0J) for analyses. The test-retest reliability of the measurements was estimated by calculating intraclass correlation coefficients (ICC), using the baseline and the $2^{\text {nd }}$ assessment outcome of Group 2. Means and SDs were calculated for each continuous variable. Differences in baseline characteristics between Groups 1 and 2 were tested with a $t$-test for continuous variables and with the chi-square test for categorical variables. Nonnormally distributed variables such as FES and EQ5D were compared with the Mann Whitney U test. Two-by-two repeated-measures analysis of variance (ANOVA), with measurement change in each phase as a dependent variable and the group and phase as independent variables, was used to examine differential improvement in primary outcomes ( $\Delta$ Baseline- $2^{\text {nd }}$ assessments and $\Delta 2^{\text {nd }}-3^{\text {rd }}$ assessments) between Groups 1 and 2 . Significance values ( $P$ values) were calculated for interactions between the group and phase for subjects who completed the trial.

For the variables with significant group-by-phase interactions, a paired $t$ test was used to examine differences between pre- and post-training measurements, with baseline and $2^{\text {nd }}$ assessments as pre-training measurements for Group 1 and Group 2, respectively, and $2^{\text {nd }}$ and $3^{\text {rd }}$ assessments as post-training measurements for Group 1 and Group 2, respectively. Comparison of the nonnormally distributed variables such as FES and EQ5D was made with the two-sided Wilcoxon's signed rank test in each group. Then, the combined data of two groups were analyzed also with the two-sided Wilcoxon's signed rank test.

For the variables with significant inter-group differences at baseline, two-by-two repeated-measures analysis of covariance (ANCOVA), with measurement change from the baseline value ( $\Delta$ Baseline- $2^{\text {nd }}$ assessments and $\Delta$ Baseline- $3^{\text {rd }}$ assessments) as a dependent variable, the group and phase (Baseline $-2^{\text {nd }}$ or Baseline- $3^{\text {rd }}$ ) as independent 
variables, and the baseline value as an independent covariate, was used to rule out possible confounding by the baseline differences. $P$ values were calculated for interactions between groups and phases. Statistical significance was set at $P<.05$.

\section{Results}

Subject flow through the trial is illustrated in Figure 1. In the four nursing homes, consent was obtained from 54 subjects. Of the 54 who completed the baseline assessments, 44 completed the immediate-intervention phase of the trial (19 in Group 1 and 25 in Group 2). A total of 40 subjects completed the entire intervention (17 in Group 1 and 23 in Group 2). Reasons for dropout were transfer out of the facility (1 subject), hospitalization because of chronic illness ( 3 subjects), and absence on the day of the assessment for private reasons (10 subjects). Statistical analyses were completed per protocol.

$<$ Insertion position of figure 1>

The ICCs 2.1 were 0.93 (standard error of the measurement: SEM=0.04) for quadriceps strength, $0.84(\mathrm{SEM}=0.12)$ for toe flexor strength, $0.58(\mathrm{SEM}=0.87)$ for one leg standing with eyes open, $0.39(\mathrm{SEM}=0.25)$ for one leg standing with eyes closed, 0.72 $(\mathrm{SEM}=1.05)$ for functional reach, $0.87(\mathrm{SEM}=0.05)$ for gait speed, $0.13(\mathrm{SEM}=3.46)$ for cadence, $0.80(\mathrm{SEM}=0.50)$ for $\mathrm{TUG}, 0.82(\mathrm{SEM}=1.29)$ for stepping in sitting, and 0.83 ( $\mathrm{SEM}=0.99$ ) for stepping in standing. The one leg standing with eyes closed and cadence measures showed low ICCs.

Baseline data for the subjects who completed the intervention are summarized in Table 1. Age, height, and weight of the two groups were not significantly different. Significant differences were seen in toe flexor strength $(P=.032)$ and stepping in standing $(P=.040)$. 
No major health problems, including cardiovascular or musculoskeletal complications, occurred during the training sessions or the testing sessions.

$<$ Insertion position of table 1>

The participation rates for training program were $57.3 \pm 29.9 \%$ in Group 1 and $67.6 \pm 30.0 \%$ in Group 2, without a significant inter-group difference $(P=.291)$.

Table 2 shows the change in muscle strength and physical function in the intervention and control phases in each group. There was a significant group-by-phase interaction in quadriceps strength $(P=.015)$, toe flexor force $(P=.009)$, functional reach $(P=.027)$, and stepping in sitting $(P=.003)$.

The results of the paired $t$ test are presented in Figure 2. Significant differences between pre- and post-training measurements were seen in all outcome measures with significant group-by-phase interaction $(P<.05)$.

<Insertion position of table 2 and figure 2>

FES was significantly improved in Group 2 during the intervention phase (Group 1, pre: 18.5 [10-32], post: 18.1 [10-33] $P=0.534$, Group 2, pre: 20.3 [10-34], post: 18.3 [10-29] $P=0.049)$. A significant improvement was found in EQ5D in Group 2 during the intervention phase (Group 1, pre: 0.73 [0.37-1.0], post: 0.73 [10-1.0] $P=0.683$, Group 2, pre: $0.69[0.53-1.0]$, post: $0.78[0.587-1.0] P=0.004)$. When the data were combined from both groups, FES was not significantly improved in the intervention phase (pre: 19.5 [10-32], post: 18.2 [10-33] $P=0.054$ ) (Figure 3). There was no significant change during the control phase in FES (pre: 19.2 [10-33], post: 19.1[10-33] $P=0.598$ ). A significant improvement was found in EQ5D, combined from both groups, during the 
intervention phase (pre: 0.708 [0.37-1.0], post: 0.755 [0.483-1.0], $P=0.01$ ) (Figure 3). There was no significant change in the control phase in EQ5D (pre: 0.70 [0.334-1.0], post: $0.71[0.37-1.0] P=0.467)$.

The results of ANCOVA showed significant group-by-phase interactions in quadriceps strength $(P=.022)$, functional reach $(P=.002)$, and stepping in sitting $(P=.022)$, but not in toe flexor strength $(P=.066)$.

$<$ Insertion position of figure 3>

\section{Discussion}

In this study, we designed an exercise program for subjects in a sitting position, with an emphasis on toe and ankle function, as a relatively safe method of training. Results showed significant improvements in quadriceps strength, functional reach, stepping in sitting, and toe flexor force, together with a possible improvement in EQ5D.

The effect on toe flexor strength, if any, is not surprising because the program focuses mainly on toe function. The improvement in quadriceps strength, in spite of the lack of direct training, can probably be attributed to the "weight-bearing on toes" exercise, because it resembles the initial phase of standing from a chair that recruits the quadriceps muscles to extend the knee joints while the toes remain on the floor. The improvement in stepping may be due to the hip flexion movement included in the program. The stepping test requires rapid hip flexion and, therefore, high activity in the hip flexor muscles. The "beanbag transfer" exercise recruits the hip flexor muscles for elevation of the thigh during the transfer phase of the exercise. In addition, isometric contraction of the hip flexors occurs during the grasping phase for positional control of the foot and toes. Although the training does not include fast movements, the hip flexor activity during the exercise could be enough to induce some improvement in stepping for the participants in 
the present study. The relationship between toe flexor strength and balance has been reported previously. In the study by Endo, Miller and Alexander, the ground reaction force was assessed in 20 young adults and 20 older adults during single-leg standing with a forward reach ${ }^{28}$. Their results demonstrated a correlation between the ground reaction force on the toes and the forward shift of the base of support. They also showed a decline in the ground reaction force on the toes and a resultant reduction in the functional base of support in the older group, suggesting the importance of toe flexor strength in movements with a forward shift of the center of pressure. Mao, Li and Hong investigated the plantar force in Tai Chi exercise and reported higher toe pressure with unstable posture ${ }^{14}$. These results indicate an important contribution of toe function to dynamic balance. The functional reach test includes a forward shift of the center of pressure. Improvement in toe function could be one of the factors involved in the increase in reach distance in the present study. While the intervention resulted in better dynamic balance, there was no significant improvement in static balance, as assessed by the timed one-leg standing test. As shown in a systematic review ${ }^{3}$, improvement in muscle strength does not lead directly to better static balance in the elderly. There was no significant improvement in mobility, either. Several studies have demonstrated the importance of toe function in gait. Stokes and colleagues have reported the importance of toe pressure elevation during the pre-swing phase in gait ${ }^{29}$. In addition, Hessert and colleagues have shown lesser toe pressure at the pre-swing phase in older subjects and suggested its relationship with lesser propulsion at push-off ${ }^{30}$. In this study, however, there was no ripple effect on mobility, in spite of the borderline improvement in toe flexor strength. For better mobility in the elderly, more dynamic training is probably required in addition to exercise in a sitting position.

The intervention resulted in some improvement in EQ5D score. A systematic review has shown a positive effect of exercise on HRQOL in healthy older people ${ }^{31}$. The 
participants in the present study possibly gained confidence in their health by the improvement in some aspects of physical function and showed higher HRQOL scores.

In the present study, the baseline physical function of the subjects was low, even compared with age-matched individuals in the community. For example, the gait speed was $1.13 \pm 1.16 \mathrm{~m} / \mathrm{s}$ in Group 1 and $0.98 \pm 0.36 \mathrm{~m} / \mathrm{s}$ in Group 2, while a gait speed of $1.59 \pm 0.28 \mathrm{~m} / \mathrm{s}$ was reported for community-dwelling older women of a similar age ${ }^{32}$. This implies low physical function in the present participants and probably explains, at least in part, why the low-intensity training resulted in improvements in some aspects of physical function. A significant group-by-phase interaction was not found in toe flexor strength by ANCOVA $(P=.066)$ with the baseline value as the independent covariate, despite the significant group-by-phase interaction by ANOVA. Thus, confounding by the baseline difference with regard to the training effect on toe flexor strength remains possible. Still, the clear significance shown by ANOVA $(P=0.01)$ and the borderline result by ANCOVA justify further investigation in this respect.

This study has several limitations. First, the subjects were not randomized. They were sampled from four nursing homes, and the four facilities were divided into two groups, resulting in significant inter-group differences in some of the measurements at baseline. To compensate, the trial was conducted with a cross-over design, and the ANCOVA was included with the baseline value as an independent covariate. This strategy probably reduced the possibility of confounding by the baseline differences and by the environmental factor in each cluster. Still, the evidence level is not as strong as would be obtained with a randomized controlled trial. Second, the data were subjected only to per protocol analysis to optimize the cross-over design. The present study cannot determine whether the intervention would be effective on an intention-to-treat basis. Third, the study lacks a detailed kinematic investigation of the training program to seek specific factors responsible for improvements in particular function. Further studies are necessary 
to clarify the mechanism by which low-intensity training improves some of the muscle strength and physical functions. It also remains to be clarified what subgroup of people shows the best trainability by this method. Finally, the change of activity level was not clarified because we didn't score activity of daily living (ADL) of the participants in this study. The direct outcome of fall was not recorded, either. The presented effect of toe and ankle training in frail people should be interpreted with caution. The effect on overall function remains unknown. Still, the findings that toe and ankle training improves physical function such as muscle strength, balance ability, and agility are of some significance. An improvement of these physical function can possibly decrease the fall risk or help frail people maintain their ambulation without increasing risks ${ }^{16}$. These assumptions need verification by further studies. A study with a larger cohort and a longer intervention period will be highly informative in assessing the effect in detail.

In conclusion, a training program that involves the individual in a sitting position and that is focused mainly on ankle, foot and toe functions is effective in improving some aspects of muscle strength, physical function and HRQOL in the elderly. This training program could be performed easily on one's own, even by elderly individuals with fall risks. This result justifies further study of low-intensity training, not necessarily requiring supervision, for the health of older persons. This approach may help them maintain their activity level without increasing risks.

\section{Acknowledgements}

We thank K. Ohata, M. Ota, S. Ogaya, K. Sakuma, R. Tsukagoshi, Y. Fukumoto, A. Konno and K. Oniki for participation in the measurements and for technical assistance. 


\section{References}

[1] Frontera W, Meredith C, O'Reilly K, Knuttgen H, Evans W. Strength conditioning in older men: skeletal muscle hypertrophy and improved function. J AppI Physiol 1988; 64: 1038-44.

[2] Fiatarone M, Marks E, Ryan N, Meredith C, Lipsitz L, Evans W. High-intensity strength training in nonagenarians. Effects on skeletal muscle. JAMA 1990; 263: 3029-34.

[3] Latham N, Bennett D, Stretton C, Anderson C. Systematic review of progressive resistance strength training in older adults. J Gerontol A Biol Sci Med Sci 2004; 59: 48-61.

[4] Judge J, Lindsey C, Underwood M, Winsemius D. Balance improvements in older women: effects of exercise training. Phys Ther 1993; 73: 254-62; discussion 63-5. [5] Rubenstein L, Josephson K, Trueblood P, et al. Effects of a group exercise program on strength, mobility, and falls among fall-prone elderly men. $J$ Gerontol $A$ Biol Sci Med Sci 2000; 55: M317-21.

[6] Binder E, Schechtman K, Ehsani A, et al. Effects of exercise training on frailty in community-dwelling older adults: results of a randomized, controlled trial. $J A m$ Geriatr Soc 2002; 50: 1921-8.

[7] Barnett A, Smith B, Lord S, Williams M, Baumand A. Community-based group exercise improves balance and reduces falls in at-risk older people: a randomised controlled trial. Age Ageing 2003; 32: 407-14.

[8] Nelson M, Fiatarone M, Morganti C, Trice I, Greenberg R, Evans W. Effects of high-intensity strength training on multiple risk factors for osteoporotic fractures. A randomized controlled trial. JAMA 1994; 272: 1909-14.

[9] Buchner D, Cress M, de Lateur B, et al. The effect of strength and endurance training on gait, balance, fall risk, and health services use in community-living older 
adults. J Gerontol A Biol Sci Med Sci 1997; 52: M218-24.

[10] Nelson M, Layne J, Bernstein M, et al. The effects of multidimensional home-based exercise on functional performance in elderly people. $J$ Gerontol A Biol Sci Med Sci 2004; 59: 154-60.

[11] Campbell A, Robertson M, Gardner M, Norton R, Tilyard M, Buchner D. Randomised controlled trial of a general practice programme of home based exercise to prevent falls in elderly women. BMJ 1997; 315: 1065-9.

[12] Menz H, Morris M. Clinical determinants of plantar forces and pressures during walking in older people. Gait Posture 2006; 24: 229-36.

[13] Tanaka T, Hashimoto N, Nakata M, Ito T, Ino S, Ifukube T. Analysis of toe pressures under the foot while dynamic standing on one foot in healthy subjects. $J$ Orthop Sports Phys Ther 1996; 23: 188-93.

[14] Mao D, Li J, Hong Y. The duration and plantar pressure distribution during one-leg stance in Tai Chi exercise. Clin Biomech (Bristol, Avon) 2006; 21: 640-5.

[15] Ihara H, Yoshida T, Takayanagi H, et al. Effect of toe and sole training on muscle power response and balance. Japanese Orthopaedic Society for Sports Medicine 1995; 15: 268.

[16] Guideline for the prevention of falls in older persons. American Geriatrics Society, British Geriatrics Society, and American Academy of Orthopaedic Surgeons Panel on Falls Prevention. J Am Geriatr Soc 2001; 49: 664-72.

[17] Wang C, Olson S, Protas E. Test-retest strength reliability: hand-held dynamometry in community-dwelling elderly fallers. Arch Phys Med Rehabil 2002; 83: 811-5.

[18] Duncan P, Weiner D, Chandler J, Studenski S. Functional reach: a new clinical measure of balance. J Gerontol 1990; 45: M192-7.

[19] Duncan P, Studenski S, Chandler J, Prescott B. Functional reach: predictive 
validity in a sample of elderly male veterans. J Gerontol 1992; 47: M93-8.

[20] Graham J, Ostir G, Kuo Y, Fisher S, Ottenbacher K. Relationship between test methodology and mean velocity in timed walk tests: a review. Arch Phys Med Rehabil 2008; 89: 865-72.

[21] Mathias S, Nayak U, Isaacs B. Balance in elderly patients: the "get-up and go" test. Arch Phys Med Rehabil 1986; 67: 387-9.

[22] Shumway-Cook A, Brauer S, Woollacott M. Predicting the probability for falls in community-dwelling older adults using the Timed Up \& Go Test. Phys Ther 2000; 80: 896-903.

[23] Buchner D, Hornbrook M, Kutner N, et al. Development of the common data base for the FICSIT trials. J Am Geriatr Soc 1993; 41: 297-308.

[24] EuroQolGroup. A new facility for the measurement of health-related quality of life. Health Policy 1990; 16: 199-208.

[25] Ikeda S. Health Status in Japanese Population : Results from Japanese EuroQol Study. Journal of Health Care and Society 1999; 9: 83-91.

[26] Team JET. The development of the Japanese EuroQol instrument. Iryo-to-shakai 1998; 8: 109-17.

[27] Tsuchiya A, Ikeda S, Ikegami N, et al. Estimating an EQ-5D population value set: the case of Japan. Health Econ 2002; 11: 341-53.

[28] Endo M, Ashton-Miller J, Alexander N. Effects of age and gender on toe flexor muscle strength. J Gerontol A Biol Sci Med Sci 2002; 57: M392-7.

[29] Stokes I, Hutton W, Stott J. Forces acting on the metatarsals during normal walking. J Anat 1979; 129: 579-90.

[30] Hessert M, Vyas M, Leach J, Hu K, Lipsitz L, Novak V. Foot pressure distribution during walking in young and old adults. BMC Geriatr 2005; 5: 8.

[31] Gillison F, Skevington S, Sato A, Standage M, Evangelidou S. The effects of 
exercise interventions on quality of life in clinical and healthy populations; a meta-analysis. Soc Sci Med 2009; 68: 1700-10.

[32] Steffen T, Hacker T, Mollinger L. Age- and gender-related test performance in community-dwelling elderly people: Six-Minute Walk Test, Berg Balance Scale, Timed Up \& Go Test, and gait speeds. Phys Ther 2002; 82: 128-37. 


\section{Figure legends}

Figure 1. Flow of subjects through the trial.

Figure 2. Pre- and post-training comparison of outcomes with significant group-by-phase interaction. $* P<.05, * * P<.01$. Significance was tested using paired $\mathrm{t}$ tests.

Figure 3. Pre- and post-training comparison of outcomes in FES (fall efficacy scale) and EQ5D (Euro Qol). ${ }^{*} P<.05$. Significance was tested using Wilcoxon's signed rank test. 
Table 1. Baseline Characteristics (Mean \pm SD) of subjects who completed the intervention

\section{Group 1 Group 2}

Characteristic

Immediate intervention Delayed intervention

\begin{tabular}{|c|c|c|}
\hline & \\
\hline & $(n=17)$ & $(\mathbf{n}=\mathbf{2 3})$ \\
\hline Age, (range) & $81.8 \pm 7.6(71-94)$ & $83.8 \pm 5.5(74-95)$ \\
\hline Female $(\%)$ & 94.1 & 87 \\
\hline Height & $145.4 \pm 7.3$ & $149.3 \pm 9.1$ \\
\hline Weight (kg) & $50.3 \pm 7.6$ & $50.4 \pm 10.1$ \\
\hline Quadriceps strength $(\mathrm{N} \mathrm{m} / \mathrm{kg})$ & $1.02 \pm .29$ & $0.89 \pm .30$ \\
\hline Toe flexor strength* (N/kg) & $2.39 \pm 1.06$ & $1.70 \pm .86$ \\
\hline $\begin{array}{l}\text { One leg standing with eye } \\
\text { open }(\mathrm{sec})\end{array}$ & $15.0 \pm 19.0$ & $4.8 \pm 7.3$ \\
\hline One leg standing with eye & & \\
\hline closed (sec) & $3.2 \pm 2.9$ & $1.9 \pm 1.6$ \\
\hline Functional reach $(\mathrm{cm})$ & $23.8 \pm 6.5$ & $20.0 \pm 7.1$ \\
\hline Gait speed $(\mathrm{m} / \mathrm{s})$ & $1.13 \pm 1.16$ & $0.98 \pm .36$ \\
\hline Cadence (step/min) & $124.3 \pm 25.0$ & $125.1 \pm 25.4$ \\
\hline Timed up and go (sec) & $10.8 \pm 4.5$ & $10.3 \pm 3.1$ \\
\hline Stepping in sitting (step) & $30.2 \pm 8.8$ & $25.6 \pm 8.8$ \\
\hline Stepping in standing* (step) & $18.1 \pm 7.9$ & $13.4 \pm 8.0$ \\
\hline Fall efficacy scale (range) & $18.5(10-32)$ & $20.1(10-32)$ \\
\hline Euro Qol (range) & $0.73(0.37-1.0)$ & $0.69(0.33-1.0)$ \\
\hline
\end{tabular}

$* P<.05$. Significance was tested using chi-square tests for categorical variables, $\mathrm{t}$ tests for continuous variables and the Mann-Whitney U test for nonnormally distributed variables. 
Table 2. Change in muscle strength and physical function (Mean \pm SD) in the intervention and control phases

Measures and outcomes

Group $1(n=17)$

Group $2(\mathbf{n}=23)$

$\boldsymbol{P}-$

value

intervention control intervention control

\begin{tabular}{lccccc}
\multicolumn{1}{c}{ phase } & phase & phase & phase & \\
\hline Quadriceps strength $(\mathrm{N} \mathrm{m} / \mathrm{kg})^{*}$ & $0.09 \pm 0.13$ & $-0.04 \pm .21$ & $0.07 \pm 0.08$ & $0.04 \pm 0.12$ & .015 \\
Toe flexor strength** (N/kg) & $0.20 \pm 0.45$ & $-0.19 \pm 0.66$ & $0.24 \pm 0.37$ & $-0.06 \pm 0.47$ & .009 \\
One leg standing with eyes & & & & & \\
open (sec) & $-2.9 \pm 6.5$ & $12.0 \pm 5.9$ & $2.6 \pm 4.1$ & $-0.9 \pm 5.4$ & .827 \\
One leg standing with eyes & & & & & \\
closed (sec) & $-0.3 \pm 3.86$ & $0.7 \pm 4.5$ & $0.3 \pm 1.4$ & $-0.4 \pm 1.9$ & .525 \\
Functional reach* (cm) & $0.7 \pm 4.1$ & $-2.5 \pm 4.1$ & $1.9 \pm 3.2$ & $0.12 \pm 5.3$ & .027 \\
Gait speed (m/s) & $0.03 \pm 0.22$ & $0.04 \pm 0.18$ & $0.07 \pm 0.13$ & $0.01 \pm 0.19$ & .587 \\
Cadence (time/min) & $22.3 \pm 44.3$ & $-0.26 \pm 35.3$ & $5.6 \pm 15.8$ & $-0.82 \pm 31.1$ & .110 \\
Timed up and go (sec) & $0.86 \pm 2.1$ & $-1.75 \pm 2.5$ & $-0.6 \pm 1.3$ & $0.1 \pm 1.8$ & .176 \\
Stepping in sitting*(step) & $2.4 \pm 6.3$ & $0.8 \pm 5.5$ & $23.2 \pm 8.8$ & $25.6 \pm 8.8$ & .003 \\
Stepping in standing (step) & $-0.1 \pm 6.1$ & $1.5 \pm 4.1$ & $1.3 \pm 3.0$ & $-0.7 \pm 4.1$ & .839 \\
\hline
\end{tabular}

$* P<.05, * * P<.01$. Significance was tested using ANOVA for group-by-phase interactions. 


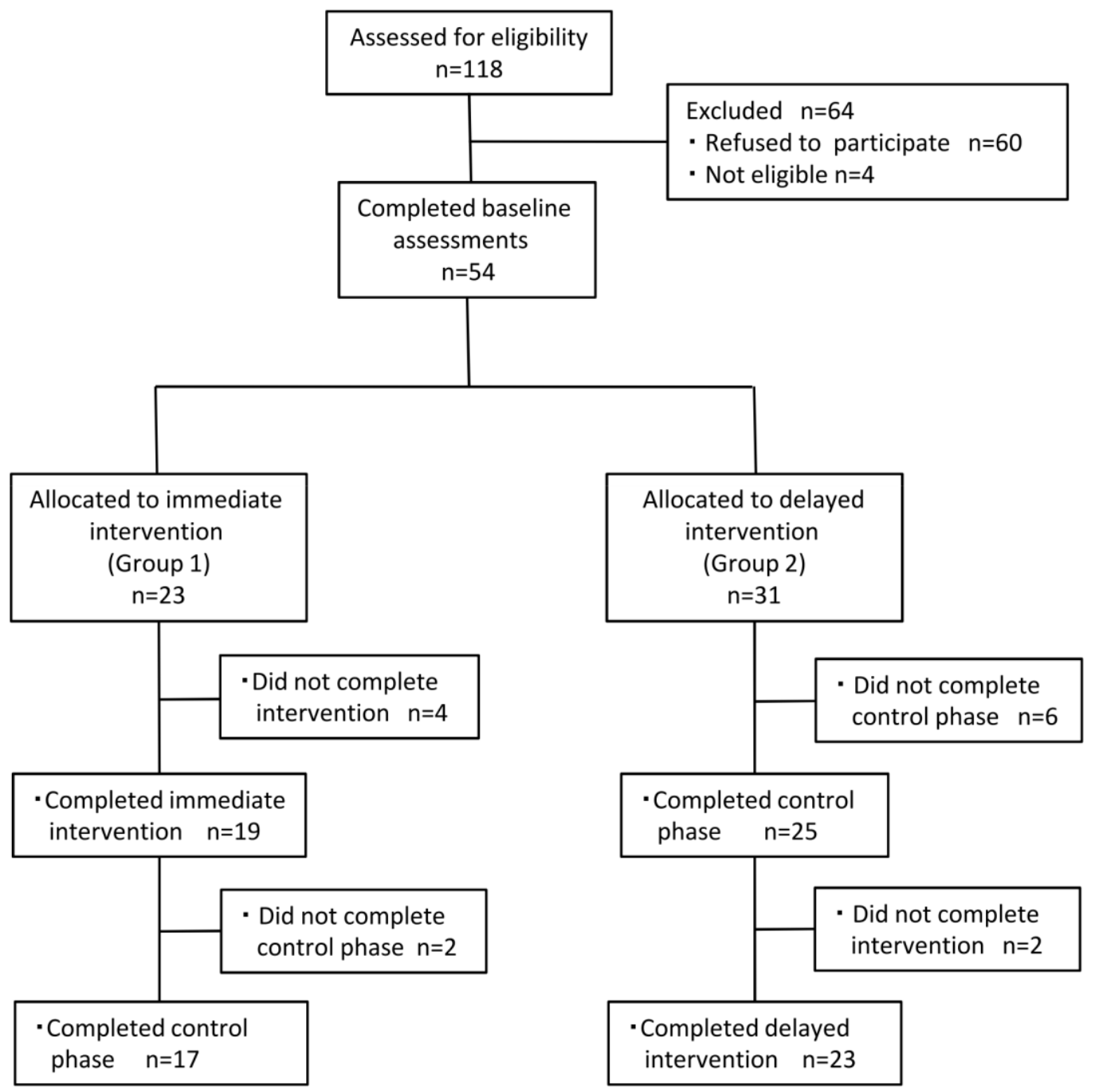

Figure 1. 


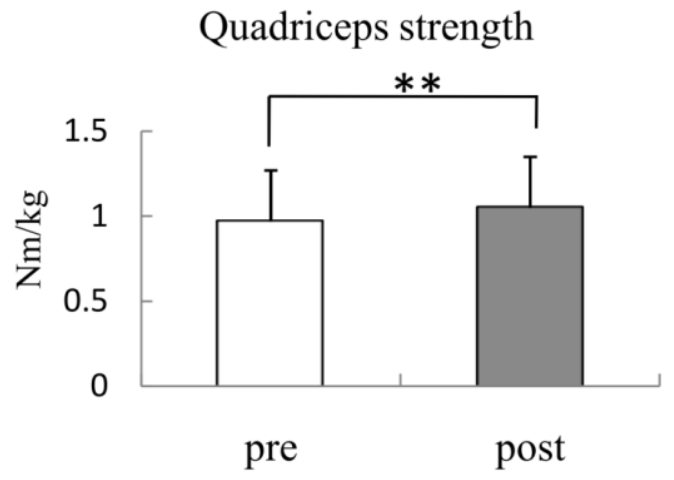

Functional reach

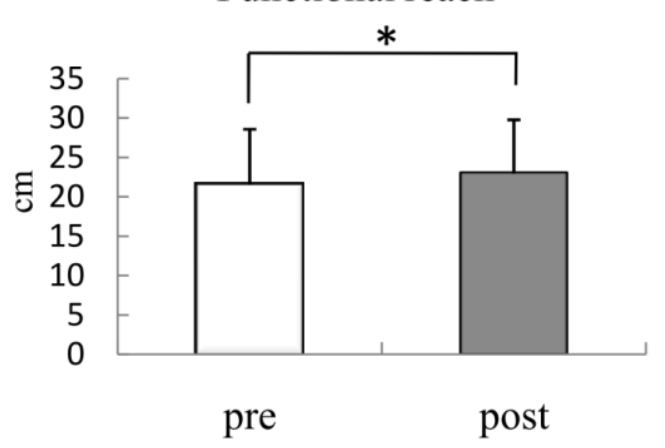

Toe flexor strength

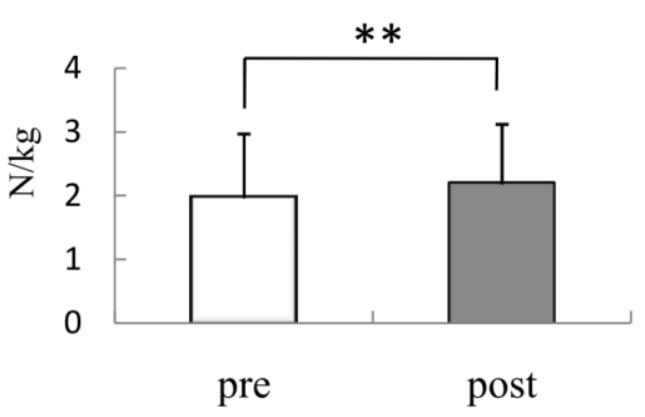

Stepping on sitting

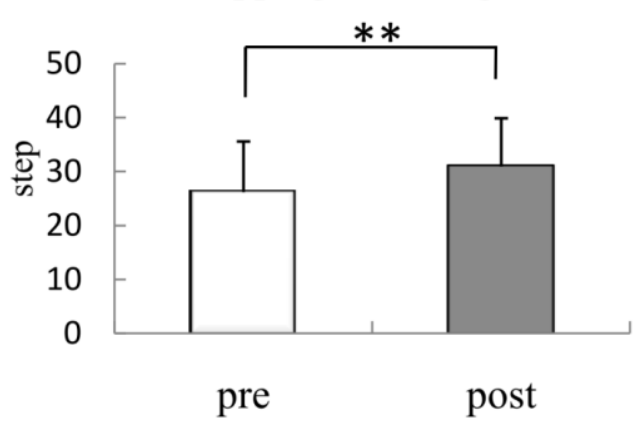

Figure 2. 
Fall Efficacy Scale

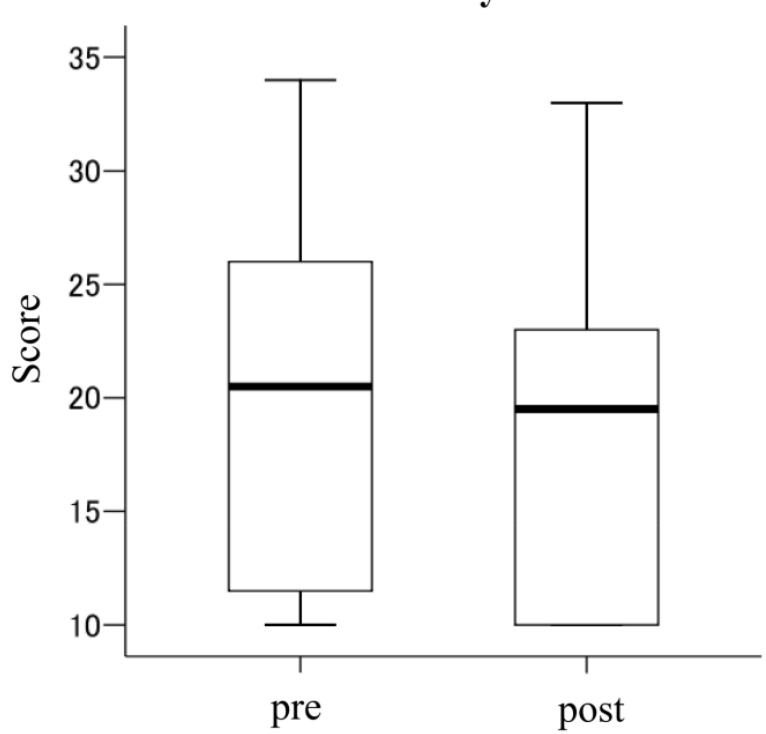

Euro Qol*

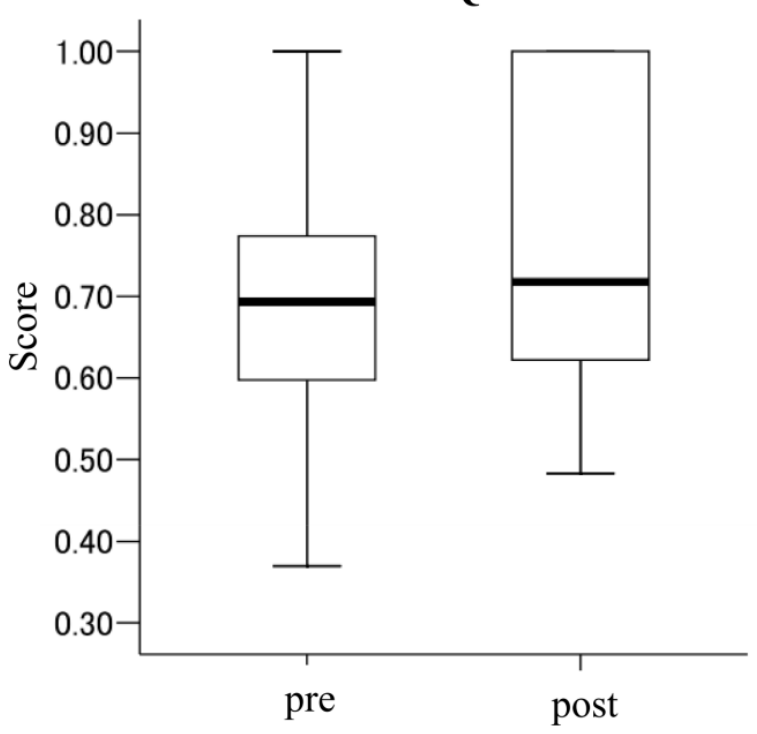

Figure 3. 